\title{
Representative model and flow characteristics of open pore cellular foam and potential use in proton exchange membrane fuel cells
}

\author{
J. G. Carton ${ }^{1 *}$, A. G. Olabi ${ }^{2}$ \\ 1. Department of Manufacturing and Mechanical Engineering, Dublin City University, Dublin 9, \\ Ireland. \\ 2. Institute of Engineering and Energy Technologies, University of the West of Scotland, Paisley, PA1 \\ 2BE, Scotland \\ *Email: james.carton3@mail.dcu.ie Phone: +353 876328459
}

\section{Highlights}

- A Representative Unit Cell Structure (RUCS) model for Open Pore Cellular Foam (OPCF) material was proposed and developed.

- Pressure drop calculations from the simulations are similar to, and matched very well with, available ERG experimental results, Dupuit-Forchheimer, Fourie \& Du Plessis, and Ashby mathematical models.

- Open Pore Cellular Foam (OPCF) material can ensure a tortuous gas flow through the structure and provide a low pressure drop from inlet to outlet.

\begin{abstract}
This study develops a Representative Unit Cell Structure (RUCS) model for Open Pore Cellular Foam (OPCF) material, based on a dodecahedron cell. Pressure, velocity and flow regime analysis is performed on simulation results of six different OPCFs, (10,20,30,40,45, 80 and 100ppi), at five different inlet velocities $(1 \mathrm{~m} / \mathrm{s}, 3 \mathrm{~m} / \mathrm{s}, 6 \mathrm{~m} / \mathrm{s}, 9 \mathrm{~m} / \mathrm{s} \& 12 \mathrm{~m} / \mathrm{s})$. Pressure drop results were verified by numerical models (Dupuit-Forchheimer, Ashby and Fourie and Du Plessis mathematical models) and experimental results from literature.

From this study OPCF material can have benefits if used in a PEM fuel cell; in place of or in conjunction with conventional flow plates. It is concluded that OPCF materials can reduce the permeability of the gas flow through a flow plate, creating a more tortuous path for the fluid, allowing for diffusion plus convection based flow, unlike conventional flow plates.
\end{abstract}

Keywords: PEM Fuel Cell, Flow Plate, Metal foam, OPCF, RUCS, Pressure Drop, CFD, Flow Analysis.

\section{Introduction}

The Proton Exchange Membrane (PEM) fuel cell is a low temperature electrochemical device that offers a promising, possibly green, alternative to traditional power sources, and other fuel cell types, in many applications, without air polluting issues [1-3]. PEM fuel cells use a solid polymer in the form of a solid phase proton conducting membrane as an electrolyte. PEM fuel cells have many advantages over other fuel cell types; including low temperature operation, high power density, fast start up, system robustness, flexibility of fuel type (with reformer) and reduced sealing, corrosion, shielding or leaking concerns [4]. A conventional PEM fuel cell consists of a Membrane Electrode Assembly (MEA) sandwiched between two flow plates. The flow plate distributes the fuel and oxidant to the reactive catalyst sites of the MEA. 
One of the key strategies for improving the performance of the PEM fuel cell is the effective design of the flow plate. The flow plate is a vital component of a PEM fuel cell and can constitute to $80 \%$ of the weight and $30 \%$ of the total cost in a fuel cell stack [5]. It supplies fuel and oxidant to reactive sites, collects produced current, removes reaction products, manages water through the cell and provides mechanical support for the cells in a stack [6].

By improving the design, layout and configuration of the flow plate with the use of low-cost lightweight construction materials and optimal fabrication methods, the weight, volume and cost of a PEM fuel cell stack can be reduced significantly [7].

In conventional flow fields, as the flow field length increases, the pressure decreases across the MEA from inlet to outlet, this can lead to the effectiveness of the fuel cell decreasing rapidly from inlet to outlet. Increasing the inlet pressure can increase cell performance, however it may reduce the efficiency of the system as Balance of Plant (BOP) equipment is needed to power this pressure increase [8].

As an alternative to conventional flow plates, Open Pore Cellular Foam (OPCF) materials have recently been used as a flow distributor in flow fields [9-15]. OPCF, shown in Figure 1 (a), is a relatively new class of cellular material with the ability to be manufactured with tailored mechanical, thermal and electrical properties by varying the material's relative density and cell morphology [16].

Having the ability to tailor a flow plate's design, e.g. to provide an acceptable pressure drop, can ensure improved PEM fuel cell performance. Understanding pressure gradients and developing models to simulate flow regimes through different OPCF material is therefore an important research area.

Early work by Du Plessis et al. [11] attempted to capture the relevant characteristics of OPCF based on a set of rectangular prisms. They used the results of an analytical flow analysis on this model to solve the flow through OPCFs on a larger scale with relatively good results. Lu et al. [17] took the approach of modelling fluid flow through open cell metal foams as a system of cylinders in their combined flow and heat convection model. Krishnan et al. $[18,19]$ simulated thermal transport in open cell metal foams using different periodic unit-cell geometries. The periodic unit-cell structures were constructed by assuming the pore space to be spherical and subtracting the pore space from a unit cube of the metal. Different types of packing arrangement for spheres were considered including; body centred cubic, face centred cubic and A15 lattice, which give rise to different foam structures. Effective thermal conductivity, pressure drop and Nusselt number are computed by imposing periodic boundary conditions for aluminium foams saturated with air or water. The computed values compare well with existing experimental measurements and semi-empirical models for porosities greater than $80 \%$.

The 14 sided tetrakaidecahedron cell has long been considered the optimal packing cell, first proposed by Lord Kelvin in 1887, decided upon mainly through experimentation. A study by Fourie and Du Plessis [20] used a 14-sided tetrakaidecahedron, to simulate pressure drop and flow in an open cell metal foam model. Boomsma et al. [21] also simulated flow through OPCF using the tetrakaidecahedron cell. $\mathrm{Xu}$ et al. adopted the tetrakaidecahedron model to systematically investigate the flow patterns in porous media and the relationship between fluid flow parameters and foams structure characteristics [22]. However other researchers such as Ozmat et al. [23] have noted in literature that the isotropic open pore cellular foam consists of randomly oriented polygon shaped cells that could be approximated by a dodecahedron, a model that has been researched little in literature.

From reviewing the literature OPCF materials of between 10 and 40ppi have been researched, however limited research for smaller pore sizes (greater than 40ppi) has been cited. From existing literature for values of permeability (K) \& form coefficient (C), many different values were found. Even when reviewing the same material types or models, researches produce different values, as 
shown in Table 1. $\mathrm{K}$ and $\mathrm{C}$ values depend on the porous media type, thickness, fluid type and fluid velocity. Creating a representative model of OPCF that can be used to clarify the exact conditions of fluid flow is therefore required.

Table 1 Permeability \& form coefficient of porous media, according to various researchers.

\begin{tabular}{|c|c|c|c|c|c|}
\hline $\begin{array}{c}\text { Sample } \\
\text { Powder } \\
\text { metallurgy foam }\end{array}$ & $\begin{array}{c}\text { Pore } \varnothing \\
(\mathrm{mm}) \\
0.36\end{array}$ & $\begin{array}{l}\text { Permeability } \\
\text { (K) } \mathrm{m} 2 \\
\text { 3.51E-10 }\end{array}$ & $\begin{array}{c}\text { Form coefficient } \\
\text { (C) } \mathrm{m}-1 \\
\\
6.95 \mathrm{E}+03\end{array}$ & $\begin{array}{c}\text { Reference } \\
\text { Loya et al. [24] }\end{array}$ & $\begin{array}{c}\text { Notes } \\
-\end{array}$ \\
\hline $\begin{array}{c}\text { Powder } \\
\text { metallurgy foam }\end{array}$ & 0.69 & $1.34 \mathrm{E}-10$ & 1.07E-02 & Loya et al. [24] & - \\
\hline 10ppi & - & 1.00E-07 & 2.10E-02 & Dukhan (2006) [25] & - \\
\hline 10ppi & - & 1.67E-07 & $9.30 \mathrm{E}-02$ & Haack et al. [26] & - \\
\hline 10ppi & - & 1.76E-07 & $4.91 \mathrm{E}+01$ & Dukhan (2010) [27] & $\begin{array}{c}\text { 0-15vel } \\
\text { discrepancy }\end{array}$ \\
\hline 20ppi & - & $6.30 \mathrm{E}-08$ & 2.90E-02 & Dukhan (2006) [25] & - \\
\hline 20ppi & - & 1.32E-07 & $7.91 \mathrm{E}+01$ & Dukhan (2010) [27] & $\begin{array}{c}\text { 0-15vel } \\
\text { discrepancy }\end{array}$ \\
\hline 30ppi & - & 1.00E-07 & $1.50 \mathrm{E}-01$ & Haack et al. [26] & - \\
\hline 40ppi & 0.63 & 4.70E-08 & 3.80E-02 & Dukhan (2006) [25] & - \\
\hline 40ppi & 0.63 & 4.80E-08 & 7.50E-02 & Cavallini et al. [28] & - \\
\hline 40ppi & 0.63 & 1.21E-07 & $1.01 E+02$ & Dukhan (2010) [27] & $\begin{array}{c}\text { 0-15vel } \\
\text { discrepancy }\end{array}$ \\
\hline Rods & 1 & 1.72E-09 & 1.92E-01 & Wilson et al. [29] & - \\
\hline
\end{tabular}

In this paper an idealised cell structure or Representative Unit Cell Structure (RUCS) of Open Pore Cellular Foam (OPCF) is developed and a model is built, based on a dodecahedron cell. The RUCS model is further developed into a computational model using Computational Fluid Dynamic (CFD) software where boundary conditions are applied and the RUCS is characterised. Flow patterns and pressure drop analysis is performed on six different OPCFs, $(10,20,30,40,45,80$ and 100ppi), at five different inlet velocities $(1 \mathrm{~m} / \mathrm{s}, 3 \mathrm{~m} / \mathrm{s}, 6 \mathrm{~m} / \mathrm{s}, 9 \mathrm{~m} / \mathrm{s} \& 12 \mathrm{~m} / \mathrm{s})$. The velocities were chosen to match literature research and experiments, for validation purposes, while also the range selected are typical values of air flow rates within PEM fuel cells $[16,20]$. This study serves to extend knowledge in this field and to understand the performance of OPCF material for PEM fuel cell flow plate applications.

\section{$2 \quad$ Representative model}

Flows in porous media may be modelled using a macroscopic approach, where volume-averaged semi-empirical equations are used to describe flow characteristics, or a microscopic approach, where small scale flow details are simulated by considering the specific geometry of the porous medium [30]. In the first approach, small scale details are ignored and information could be lost if not represented correctly in the governing equations. In the second, the intricate geometry of the porous structures, which may cause unpredictable flow patterns to develop altering the outcome of an engineering model, are accounted for and the transport through these structures is computed. 
This approach is computationally expensive if the entire physical domain were to be simulated. However, if this approach is adopted a closer model to reality can be created and multi-physical phenomena can be viewed with greater precision, with flow and mass transfer predictions made more accurately. This study used a microscopic approach to model OPCFs. All 3-D operations to develop the model are built using SolidWorks CAD software.

Each pore of the RUCS developed in this study is represented by a dodecahedron, as researched by Ozmat et al. [23]. They concluded that the geometric characteristics of the dodecahedron are related to the physical structure of the metal foams, for example, ligament size, surface area, cell density, and relative density. A dodecahedron may be divided into twelve identical pyramids having a pentagon shaped base. When assembled, the vertexes of these pentagonal pyramids meet at the centroid of the dodecahedron. To produce a solid dodecahedron twelve pyramids can be constructed and joined together to form a solid dodecahedron. A solid dodecahedron model allows the estimation of surface area and pore volume characteristics; however a ligament structure is required to represent individual pores and to perform CFD simulations.

The structures that form pores, and connect pores to each other in open pore cellular foam, are called ligaments. These have been shown by many researchers such as Ozmat et al. [23] to have an equilateral triangular cross section. Ligaments were constructed and joined together to make a dodecahedron pore as shown in Figure 1 (b). Table 2 displays the main characteristics calculated for all OPCF materials used in this study. The mathematical formulae that were used to calculate these values and construct these pyramids \& the dodecahedron can be found at [23].

\begin{tabular}{|c|c|c|c|c|c|c|c|}
\hline Cell density $\alpha$ (ppi) & 10 & 20 & 30 & 40 & 45 & 80 & 100 \\
\hline Ligament edge length $(\mathrm{mm})$ & 1.016 & 0.508 & 0.338 & 0.254 & 0.225 & 0.127 & 0.1016 \\
\hline Pore diameter (mm) & 2.54 & 1.27 & 0.85 & 0.635 & 0.564 & 0.318 & 0.254 \\
\hline Pore volume $\left(\mathrm{mm}^{3}\right)$ & 8.034 & 1.004 & 0.2975 & 0.1255 & 0.08816 & 0.01569 & 0.00803 \\
\hline Ligament triangular side (mm) & 0.15 & 0.048 & $\mathbf{0 . 0 3 3}$ & 0.023 & 0.0154 & 0.00712 & 0.005347 \\
\hline Specific surface $\left(\mathrm{m}^{2} / \mathrm{m}^{3}\right)$ & 900 & 1266 & 1447 & 1600 & 1705 & 1795 & 1854 \\
\hline
\end{tabular}

A simple comparison was made between the dodecahedron made from the pyramids and the dodecahedron made from the ligaments to ensure that both methods produced similar geometry. The advantage of making the dodecahedron pore from ligaments ensured a less complicated model and reduced additional activates to make the solid dodecahedron into a ligament structure, as completed by researchers such as Krishnan et al. [18]. 


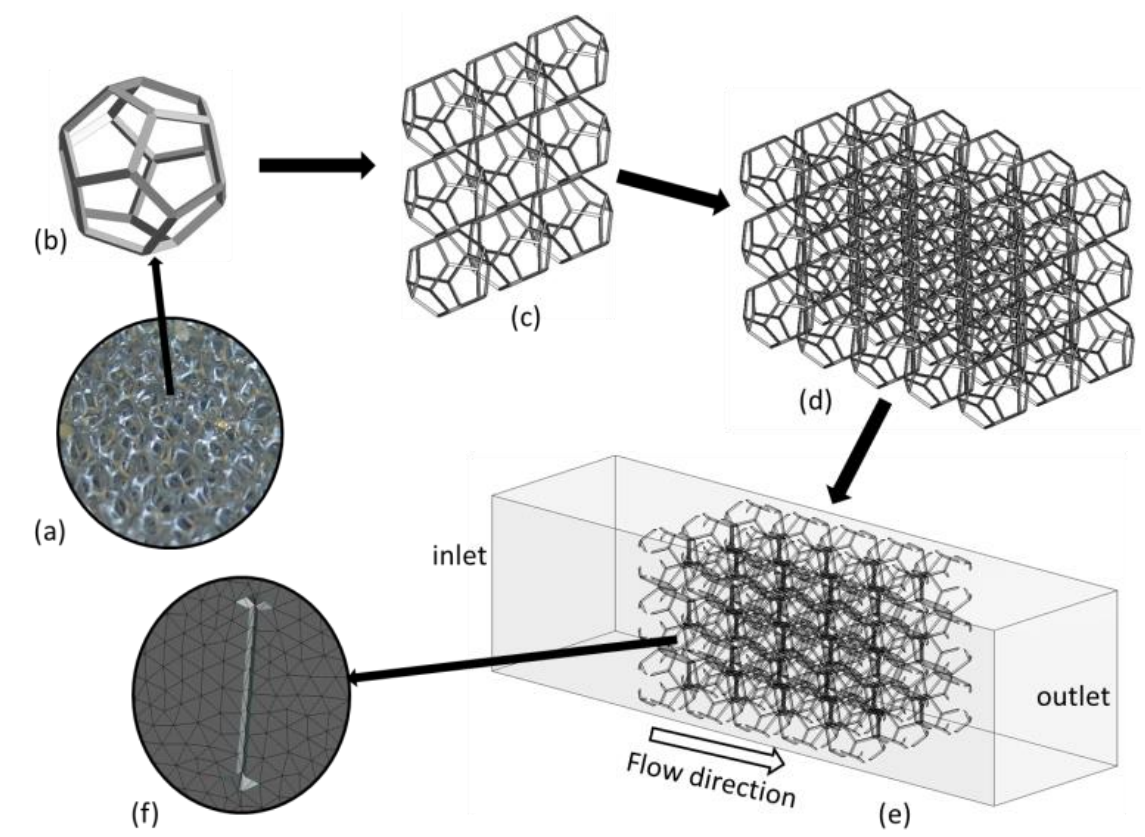

Figure 1 Dodecahedron model matrix development (a) OPCF sample (b) Doadecahedron pore (c) Pore pattern (d) Pore matrix (e) Computational domain (f) Close up of ligament surface mesh.

Having created a representative model of a single pore, a fluid volume, of representative size, is required to perform flow analysis and measurements through CFD software. A single dodecahedron pore is patterned into a matrix of pores, as shown in Figure 1 (c) \& (d). The number of pores specified and the volume of each model was determined by the pores per inch (ppi) of each sample. The matrix is contained in a volume and a boolean operation was used to subtract the matrix from the volume. A closed volume with the pore structure remained, as shown in Figure 1 (e). An inlet region and outlet region is represented in as shown in Figure 1 (e). These regions were necessary to allow the fluid time to steady state and helped characterise the flow regime better. Also wall effects were minimised as the matrix of pores protrudes to the edge of the volume. It was noted in literature [31,32] and visible in early model designs that fluid would take the easier path of skirting around the wall edges to avoid the porous region and hence this model design avoids this unwanted anomaly.

\section{Computational model}

The model was imported into commercial software, Ansys mesh, boundary conditions were added, and it was meshed using hybrid elements by specifying the minimum edge length. The CFD software version used in this study can only be used with cases containing less than 512,000 elements and so the each model has restrictions on its physical dimensions and mesh size (for example: the 10ppi model is bigger than the 100ppi model). In order to test the dependency of the results on the mesh resolution, a number of meshes were examined as shown in Figure 2. The variation of pressure drop $(\Delta \mathrm{P} / \mathrm{L})$ between successively refined meshes was less than $1 \%$, confirming mesh independence. Final models contained the most refined meshes, between $300 \mathrm{E}+03$ and $500 \mathrm{E}+03$ elements, course enough not to exceed the limit or computational power or time available, but fine enough to give acceptable results. 


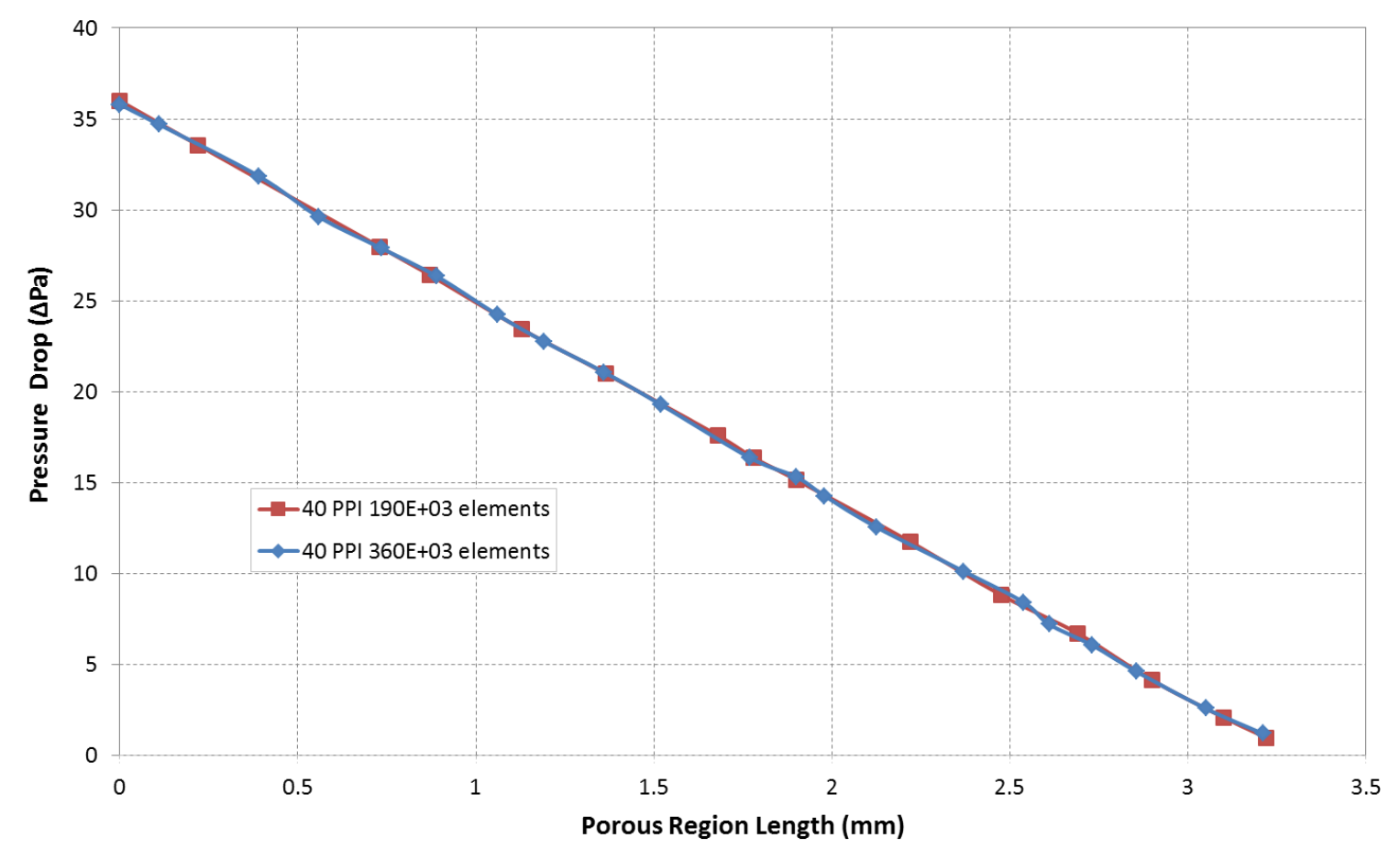

Figure $2 \Delta \mathrm{P} / \mathrm{L}$ model results at $3 \mathrm{~m} / \mathrm{s}$ for $40 \mathrm{ppi}$ model with $190 \mathrm{E}+03$ and $360 \mathrm{E}+03$ elements.

Following meshing, the boundary conditions are specified in Ansys Fluent. The analysis of the flow distribution performance is then conducted, also using commercial software Ansys Fluent. Table 3 summaries the boundary conditions, and solution parameters used in this study. The present model assumptions are: (1) steady state, (2) ideal gas, (3) single phase, (4) laminar flow, and (5) isotropic solid materials, (6) no gravity affect, similar to other researchers [33,34]. The inlet flow is laminar, due to the low flow rates used in the model, as displayed in Table 4, and thus been used in this study, similar to other researchers $[22,35,36]$. The continuity and Navier-Stokes equations can be expressed as:

$$
\begin{gathered}
\rho u \cdot \nabla u=-\nabla p+\mu \nabla^{2} u \\
\nabla \cdot u=0
\end{gathered}
$$

where $\mu$ and $\rho$ are the viscosity and density of the fluid and $u$ and $p$ are local velocity and pressure, respectively [22,37]. The density and viscosity of the air, which was used as the fluid in the simulation, are $1.225 \mathrm{~kg} / \mathrm{m} 3$ and $1.7894 \times 10-5 \mathrm{~kg} / \mathrm{m}$-s.

Several key phenomena were monitored during each simulation, until convergence, including continuity and velocity, and checks were made to ensure steady state and low residual RMS error. Flux reports were also analysed; the sum of the flux at the inlet should closely match the flux at the outlet. 
Table 3 OPCF model mesh, boundary conditions \& solution parameters.

\begin{tabular}{|c|c|c|c|c|c|}
\hline \multicolumn{2}{|c|}{ Mesh Properties } & \multicolumn{2}{|c|}{ Boundary Conditions } & \multicolumn{2}{|c|}{ Solution Parameters } \\
\hline Mesher & Ansys Meshing & Model & OPCF & Solver & $\begin{array}{c}\text { Fluent 3-D Double } \\
\text { Precision }\end{array}$ \\
\hline Mesh & Mixed Tet. \& Quad. & Viscous model & Laminar & Solver type & Pressure based \\
\hline Relevance & Fine & Fluid & Air & Scheme & Simple \\
\hline Size function & Fixed & Solid & Aluminium & Gradient & $\begin{array}{l}\text { Least squares cell } \\
\text { based }\end{array}$ \\
\hline Smoothing & Medium & Temperature & $288 K$ & $\begin{array}{c}\text { Discretization } \\
\text { Pressure }\end{array}$ & Standard \\
\hline Transition & Slow & Inlet velocity $(\mathrm{m} / \mathbf{s})$ & $1-12$ & $\begin{array}{c}\text { Discretization } \\
\text { Momentum }\end{array}$ & $\begin{array}{l}\text { Second order } \\
\text { upwind }\end{array}$ \\
\hline Elements & $300 \mathrm{E}+03-500 \mathrm{E}+03$ & Pressure outlet $(\mathbf{P a})$ & $\mathbf{0}$ & $\begin{array}{c}\text { Solution } \\
\text { Initialization }\end{array}$ & $\begin{array}{c}\text { Compute from } \\
\text { Inlet }\end{array}$ \\
\hline
\end{tabular}

\begin{tabular}{|c|c|c|c|}
\hline \multicolumn{5}{|c|}{ Table 4 OPCF model flow characteristics. } \\
\hline $\begin{array}{c}\text { Flow Rate } \\
(\mathbf{m} / \mathbf{s})\end{array}$ & $\begin{array}{c}\text { Reynolds Number } \\
(\text { Re })\end{array}$ & Flow Type & $\begin{array}{c}\text { Peclet Number } \\
(\text { Pe })\end{array}$ \\
\hline 0 & $\mathbf{0}$ & Laminar & $\mathbf{0}$ \\
\hline 1 & $\mathbf{2 0 5}$ & Laminar & $\mathbf{1 3 0}$ \\
\hline 3 & $\mathbf{6 1 6}$ & Laminar & $\mathbf{3 9 1}$ \\
\hline 6 & $\mathbf{1 2 3 2}$ & Laminar & $\mathbf{7 8 1}$ \\
\hline 9 & $\mathbf{1 8 4 8}$ & Laminar & $\mathbf{1 1 7 2}$ \\
\hline 12 & $\mathbf{2 4 6 5}$ & Laminar to Transient & $\mathbf{1 5 6 3}$ \\
\hline
\end{tabular}

\section{$4 \quad$ PRESSURE DROP THROUGH POROUS MEDIA}

Pressure drop through porous materials can be determined from Darcy's law:

$$
\Delta P / L=(\mu / K) v
$$

where $\Delta \mathrm{P}$ is the pressure drop over length, $\mathrm{L}, \mu$ is the fluid viscosity, $\mathrm{v}$ is the superficial fluid velocity and $\mathrm{K}$ describes the permeability of a porous medium i.e. how easy it is for fluid to flow through it. However, Darcy's law is only applicable for Reynolds number less than one $(\operatorname{Re}<0.1)$. For high enough flow velocities $(>0.1 \mathrm{~m} / \mathrm{s}$ ) form drag (constant related to material that would hindering flow e.g. ligaments of the foam) becomes important and the hydraulic properties that now characterise a porous medium are its permeability (K) and form coefficient $(C)$. To describe the pressure drop in the foam or simultaneously determine $\mathrm{K}$ and $C$ for a porous medium at these velocities the HazenDupuit-Darcy model (also known as the Forchheimer-extended Darcy model or Dupuit-Forchheimer) is used:

$$
\Delta P / L=(\mu / K) v+\rho C v^{2}
$$


where $\rho$ is the fluid density.

Medraj et al. [24] conducted an experimental analysis on the pressure drop across simple structure metallic foams at different velocity ranges using air as the working fluid. They observed that pressure drop characteristics fit the polynomial model of Hazen-Depuit-Darcy where $\mathrm{K}$ and $\mathrm{C}$ are important values. A study performed by Dukhan [25] also found that the pressure drop increased with increasing Darcian velocity following the Hazen-Depuit-Darcy model and that the lowerporosity foam produced significantly higher pressure drop. Both $\mathrm{K}$ and $\mathrm{C}$ correlated well with the porosity. The correlations predicted the results of some previous studies reasonably well, especially for the low-pore-density foam. Wilson et al. [29] also looked at permeability and form drag coefficient of porous inserts in an experiment using rod and holes with water as the working fluid they show that their experimental data correlates to Hazen-Dupuit-Darcy model.

The Ergun equation describes flow of a fluid past a collection of uniform spherical particles of diameter $d_{p}$ :

$$
\Delta p / L=A v+B \rho v^{2}
$$

where

$$
A=150 \mu(1-\varepsilon)^{2} / \varepsilon^{3} d_{p}^{2}
$$

and

$$
B=1.75(1-\varepsilon) / \varepsilon^{3} d_{p}
$$

where $\varepsilon$ is the void space or the porosity of the material. This equation is most commonly used in flow through a packed bed; however for the purposes of correlating models and that this equation allows input of many variables that are available for open pore cellular foam materials, this equation was also used.

The pressure drop inside metal foams is described by the equation developed by Ashby et al. [9]:

$$
\Delta p / L=\xi 1 / d_{p}\left[\mu^{m} \rho /(1-\alpha)^{2-m}\right] v^{2-m} d_{L}^{-m}
$$

where $\alpha$ is the thermal diffusivity, $d_{L}$ is the foam ligament diameter and $\xi$ and $m$ are determined experimentally. Some $\xi$ and $m$ values are detailed in [9]. This equation is in the context of pressure drop in relation to heat transfer, but for the purposes of correlating models, this equation was also used.

The pressure drop inside metal foams is described by the equation developed by Fourie and Du Plessis [20].

$$
\Delta p / L=(3-\tau) \times(\tau-1) \times\left(\rho \tau^{2} v^{2} / \varepsilon^{3} d_{p}\right) \times\left(3 \mathrm{C}_{\mathrm{d} v} / 2+\mathrm{C}_{\mathrm{df}} / / 4\right) \times \varepsilon
$$

where

$$
\mathrm{C}_{\mathrm{d} v}=24 \mu \varepsilon / \rho \tau(3-\tau) d_{p} v
$$

and

$$
C_{d f}=1+10\left(\rho v^{2} d_{p}(\tau-1) / 2 \mu \varepsilon\right)^{-0.667}
$$

where $\tau$ is the tortuosity (relation to ligament structure) and $C_{d f}$ and $C_{d v}$ are drag and frictional coefficient respectively as described by Fourie and Du Plessis [20]. This equation correlated well with experiments completed by Bastawros et al. [16] and described by Lu et al. [17] and shown in Figure 3. These equations are quiet complex introducing new terms and coefficients to describe flow and pressure drop through OPCF materials. 


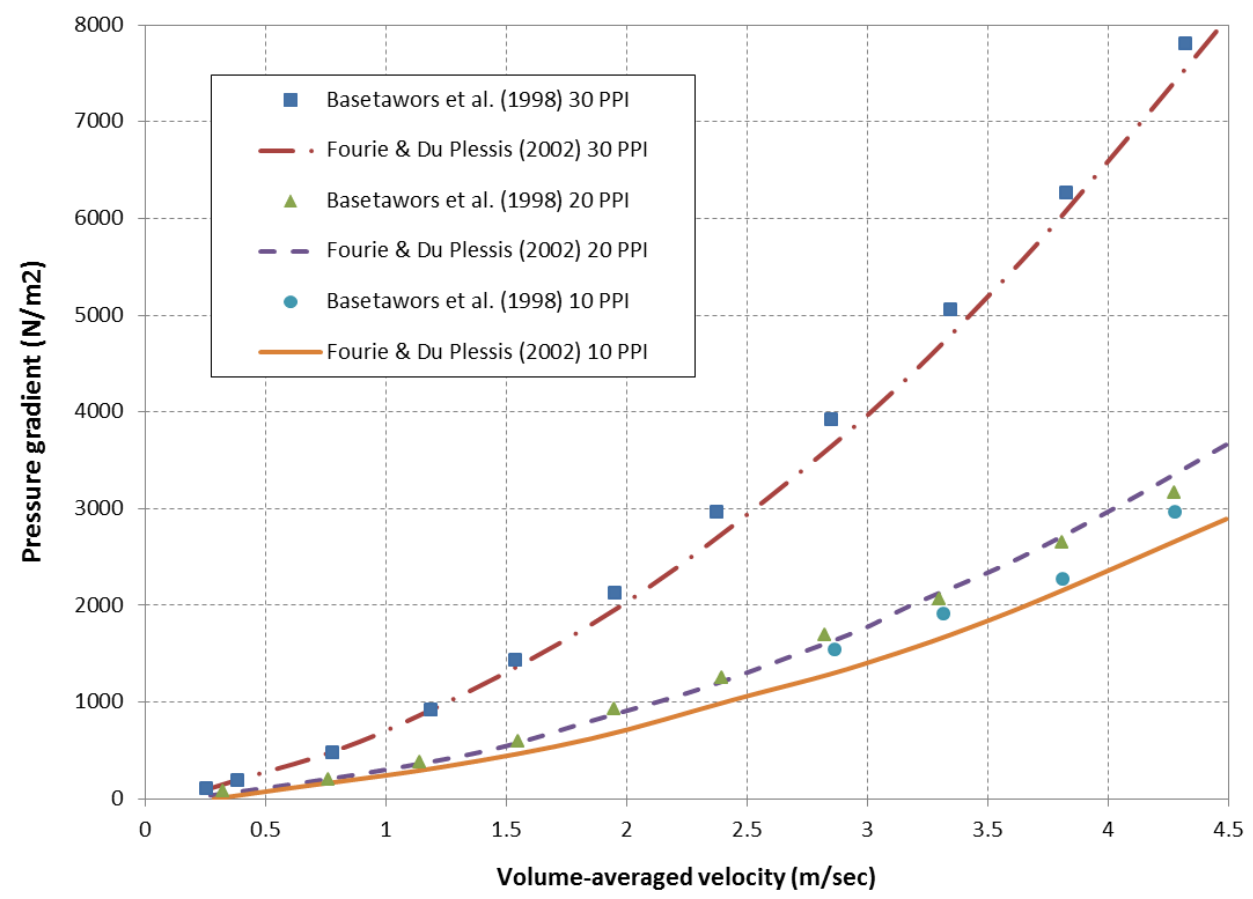

Figure 3 Pressure drops in foam material modified from [20].

To ensure an accurate RUCS model, $\mathrm{K}$ and $\mathrm{C}$ values for the test samples used in this work have been determined from experimental flow data provided from the OPCF manufacturer, ERG Aerospace, see Figure 4 [38]. Experimental data in the form of pressure drop against velocity through a porous media can be extrapolated to determine the coefficients for the porous media. A curve can be plotted to create a trend-line through these points yielding the following equation:

$$
\Delta p=A x^{2}+B x
$$

where $\mathrm{x}$ is fluid velocity, $\mathrm{v}$. With known values of fluid density and viscosity, $\mathrm{K}$ and $\mathrm{C}$ values can be calculated using:

$$
\begin{aligned}
& K=\mu / L B \\
& C=A / \rho L
\end{aligned}
$$

Or in Ansys Fluent:

$$
C=A / 0.5 \rho L
$$

where a value of 0.5 is present, which provides a correction for inertial losses in the porous medium as defined in Ansys Fluent for the case of simple homogeneous porous media [37]. In this study Equation 14 is used. 


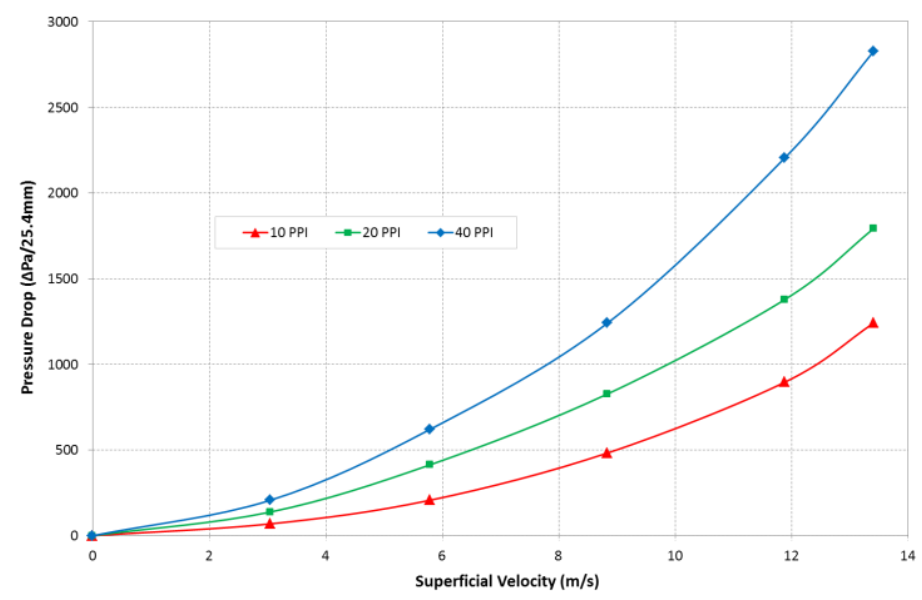

Figure 4 Pressure drop in a range of open pore cellular foams, taken from [38].

5

RESULTS

A CFD analysis was carried out on 10, 20, 30, 40, 45, 80 and 100ppi open pore cellular foam models. The main items that were analysed were pressure through the model, pressure drop from inlet to outlet, velocity flow through the model and flow regime. In addition the interaction of the fluid with the open pore cellular foam and the walls of the model were observed. Each model was examined with five different inlet velocities $(1 \mathrm{~m} / \mathrm{s}, 3 \mathrm{~m} / \mathrm{s}, 6 \mathrm{~m} / \mathrm{s}, 9 \mathrm{~m} / \mathrm{s} \& 12 \mathrm{~m} / \mathrm{s})$ to examine the fluid flows at different inlet velocities but also to compile results that can be used in post processing to calculate accurate pressure drop curves of the OPCF materials.

In the following models it is noted that all the following results should be similar and are similar to each other. As the ppi number increases more and smaller pores are in each model and the pressure drop should increase.

The results presented below are for 10, 20 and 40ppi foam models at an inlet velocities of $3 \mathrm{~m} / \mathrm{s}$. Figures 5, 7 and 9 show pressure and velocity results along the central plane of the model. The 10ppi model in Figure 5 is two pores thick and 3 pores deep, while the 40ppi in Figure 9 is three pores thick and 5 pores deep, including half pores at the edges and walls. This is due to the size reduction of the model as the ppi number increased.

\section{$5.1 \quad$ 10ppi OPCF model}

The pressure drop through the 10ppi model is small, ranging from 0.5 to 2 pascals at $1 \mathrm{~m} / \mathrm{s}$ inlet velocity to about 90 pascals at $12 \mathrm{~m} / \mathrm{s}$ inlet velocity. As the inlet velocity increases, as shown in Figure 5 , for $3 \mathrm{~m} / \mathrm{s}$, mixing at the ligaments, and at the wall is enhanced. 


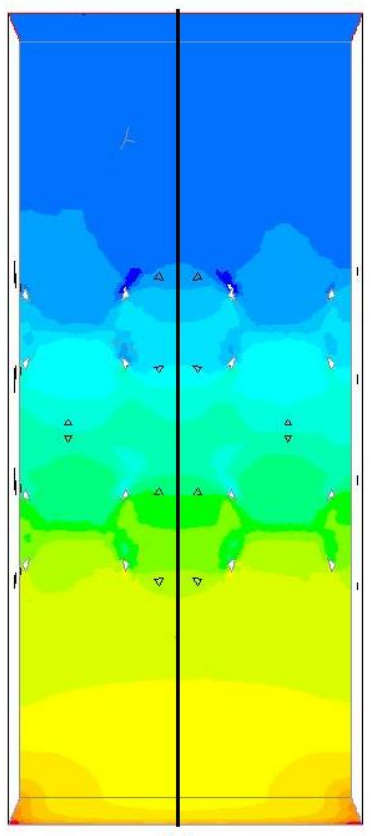

(a)
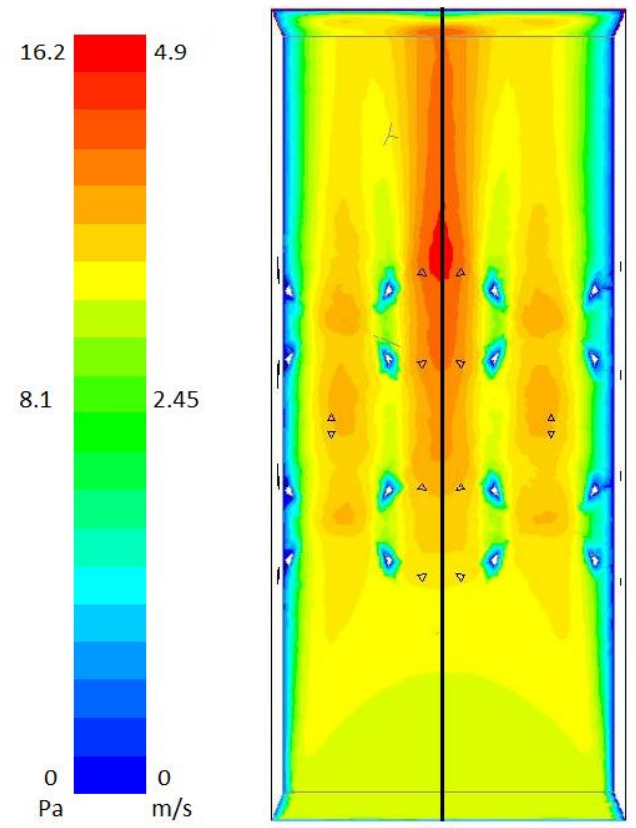

(b)

Figure 5 10ppi inlet velocity 3m/s (a) Pressure (Pa) (b) Velocity (m/s).

Figure 6 shows a normalised pressure drop for the 10ppi model. This graph characterises the 10ppi foam by the curve and a comparison of the 10ppi model to other mathematical models and models developed in literature. A good fit to the models is observed for low inlet flow velocities. As expected the Darcy (due to high Reynolds number) and the Ergun mathematical models (due to lack of spherical particles) do not align.

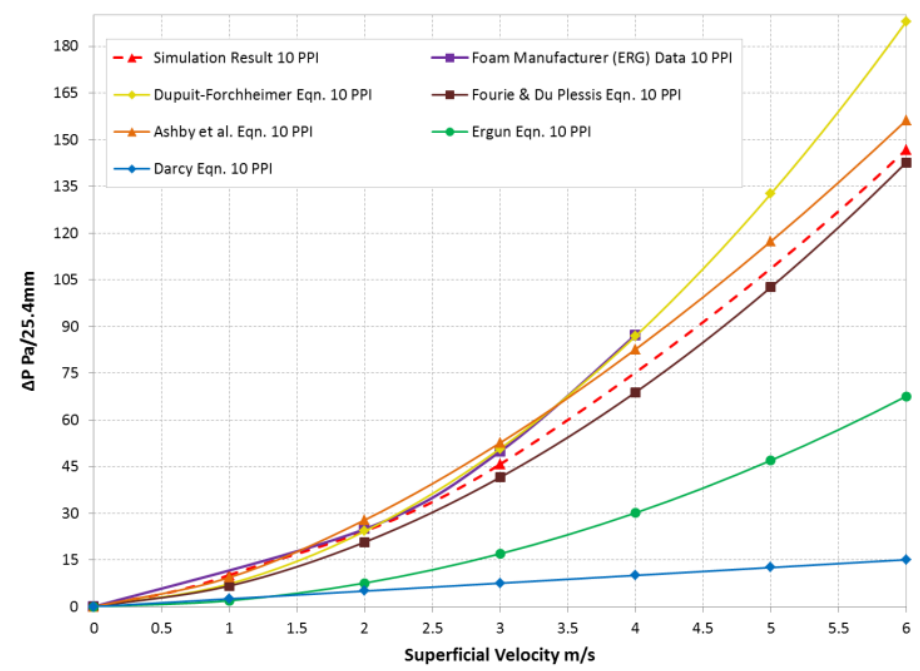

Figure 6 10ppi pressure drop comparison.

\section{$5.2 \quad 20 p p i$ OPCF model}

Similarly to the 10ppi model when the fluid comes in contact with the ligaments in the 20ppi model, the velocity increases and the fluid is diverted around the ligaments creating a convective flow through the porous region as visible in Figure 7. 

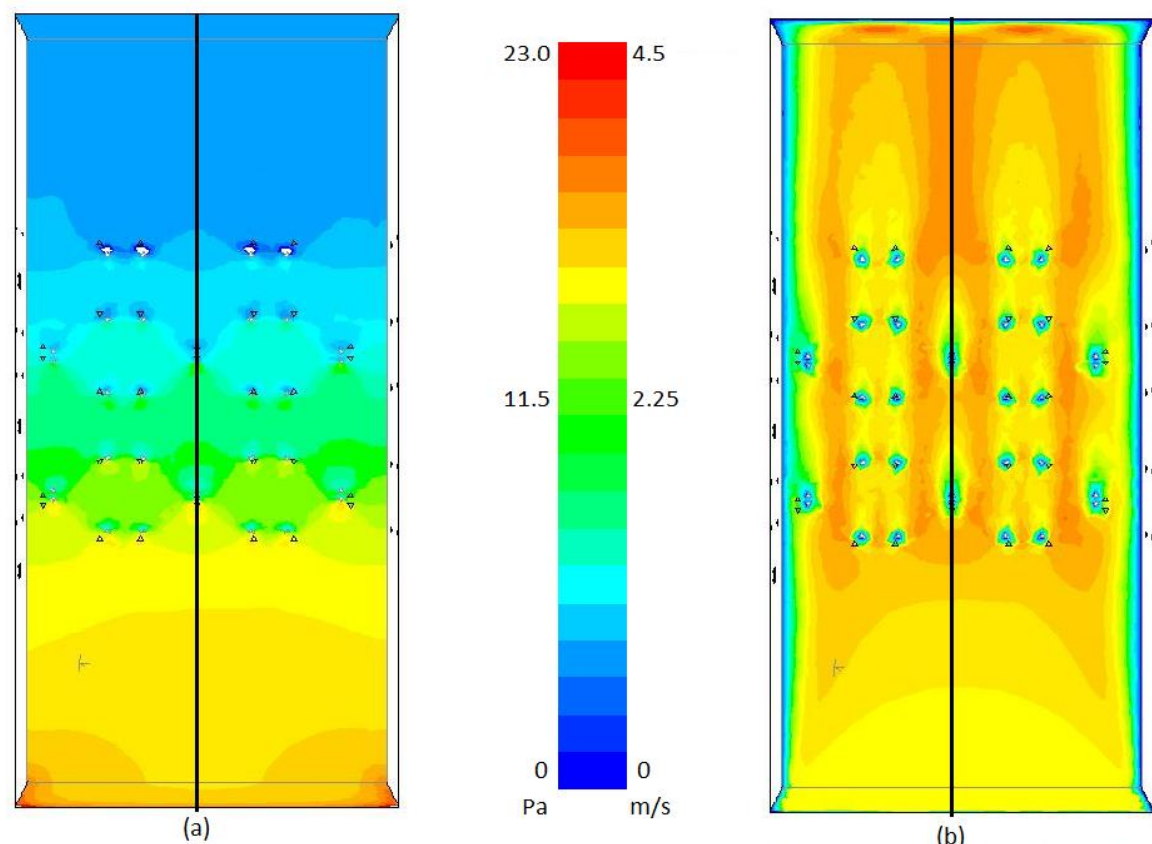

(b)

Figure 7 20ppi inlet velocity 3m/s (a) Pressure (Pa) (b) Velocity (m/s).

The pressure drop through the 20ppi model, Figure 8 , is small, ranging from 1 to 2 pascals at $1 \mathrm{~m} / \mathrm{s}$ inlet velocity to about 130 pascals at $12 \mathrm{~m} / \mathrm{s}$ inlet velocity. A good fit to the models is observed for the developed model in this study and the Dupuit-Forchheimer, however Fourie and Du Plessis and Ashby et al. equations create a steeper curve at medium inlet velocities.

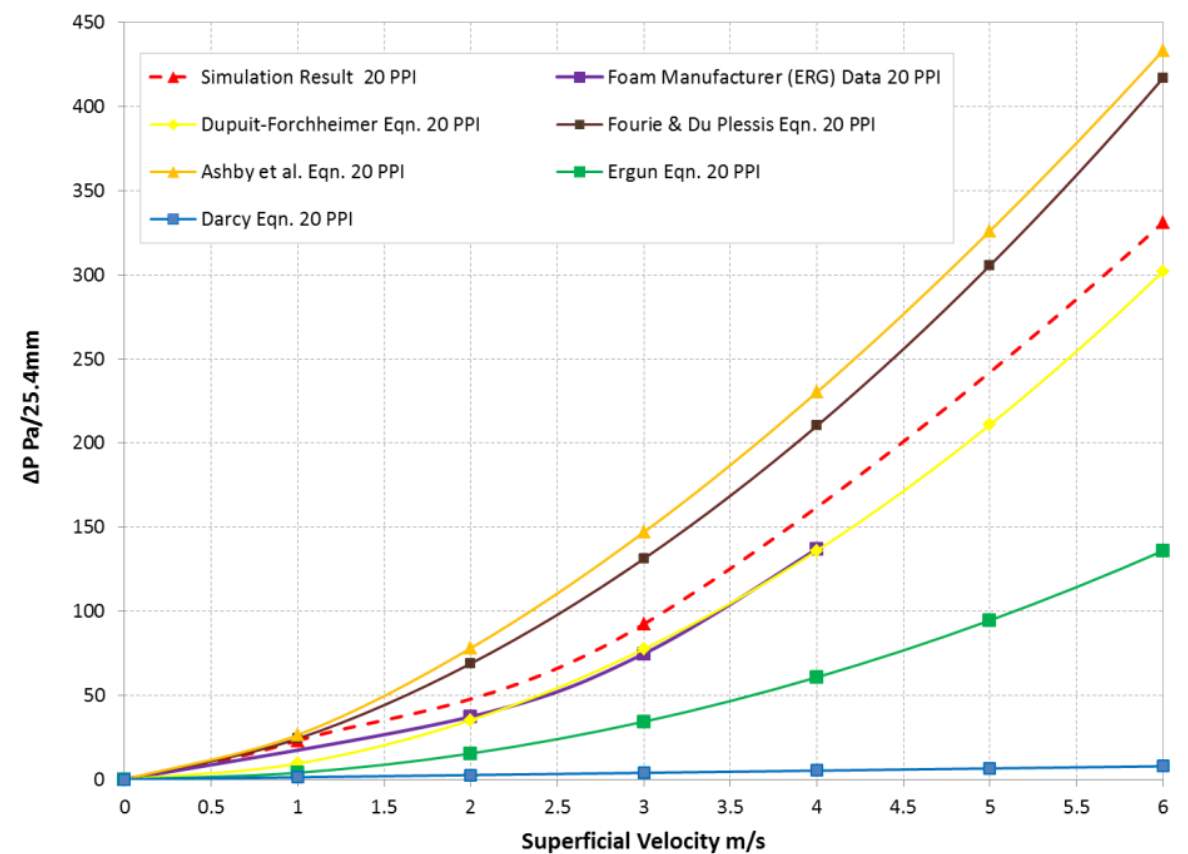

Figure 8 20ppi pressure drop comparison. 


\subsection{0ppi OPCF model}

Similarly to the previous models the fluid flow regime through the models is observed in Figure 9.

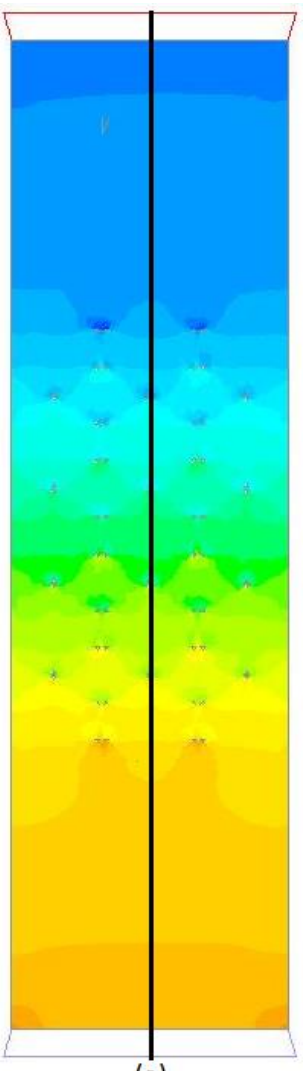

(a)

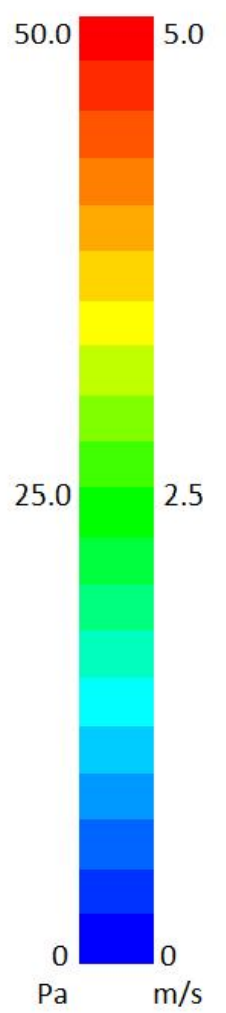

$\mathrm{m} / \mathrm{s}$

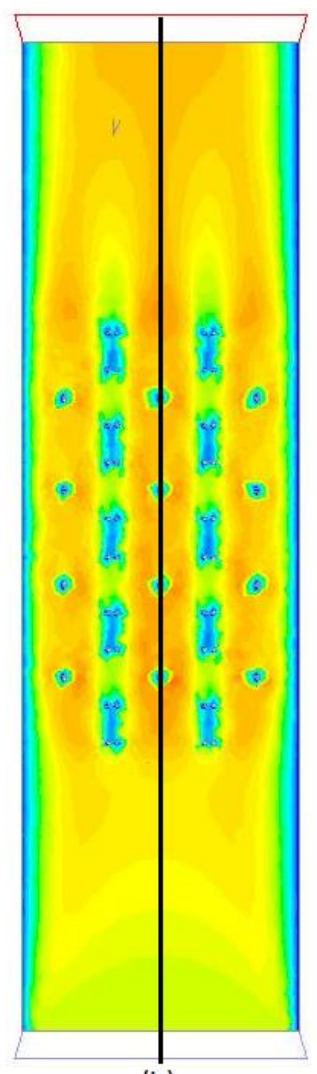

(b)

Figure 9 40ppi inlet velocity $3 \mathrm{~m} / \mathrm{s}$ (a) Pressure (Pa) (b) Velocity (m/s).

The velocity vectors are shown for the 40ppi model in Figure 10. When the fluid comes in contact with the ligaments, velocity increases and the fluid is diverted around the ligaments creating convective flow through the porous region, this can be noticed by the orange and red arrows. A closer look at the arrows of the velocity vectors of this model can illustrate the convective air flow regime. 


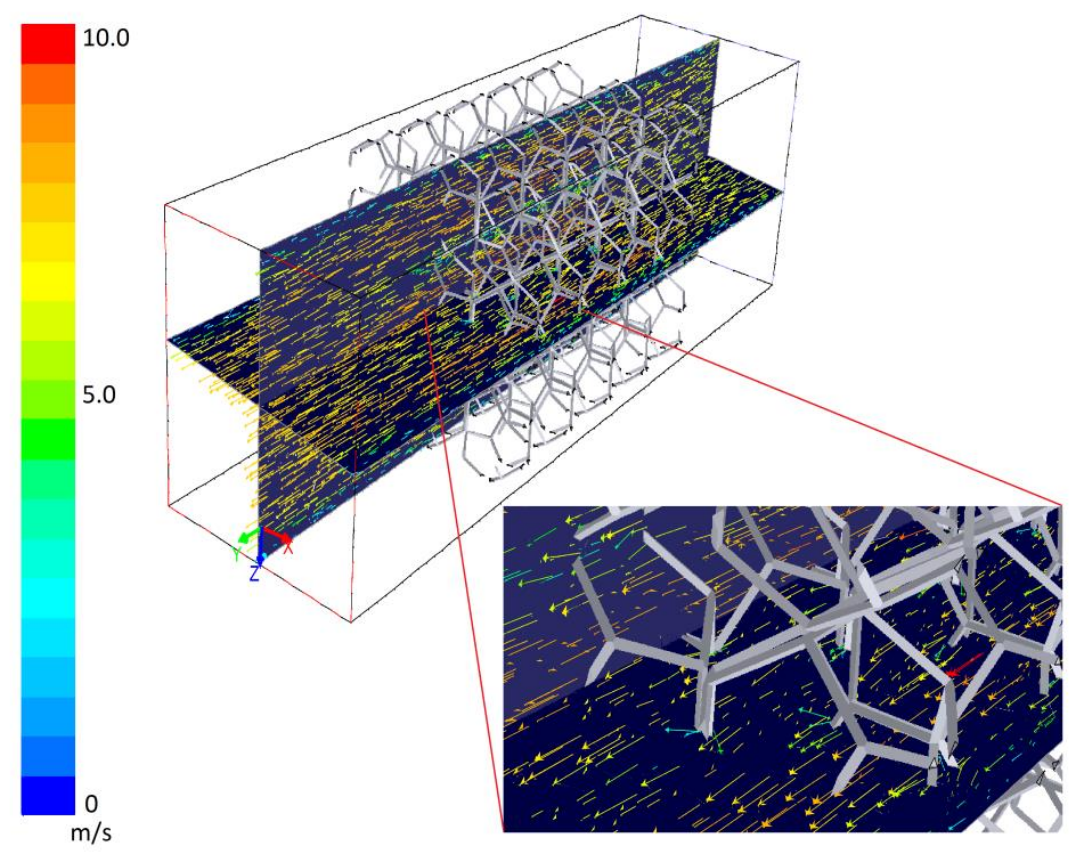

Figure 10 40ppi Velocity vectors $(\mathrm{m} / \mathrm{s})$ (inlet velocity $3 \mathrm{~m} / \mathrm{s})$.

The pressure drop through the 40ppi model is small, ranging from 6 to 8 pascals at $1 \mathrm{~m} / \mathrm{s}$ inlet velocity to about 330 pascals at $12 \mathrm{~m} / \mathrm{s}$ inlet velocity, as shown in Figure 11 . A good fit to the models is observed for low inlet flow velocities.

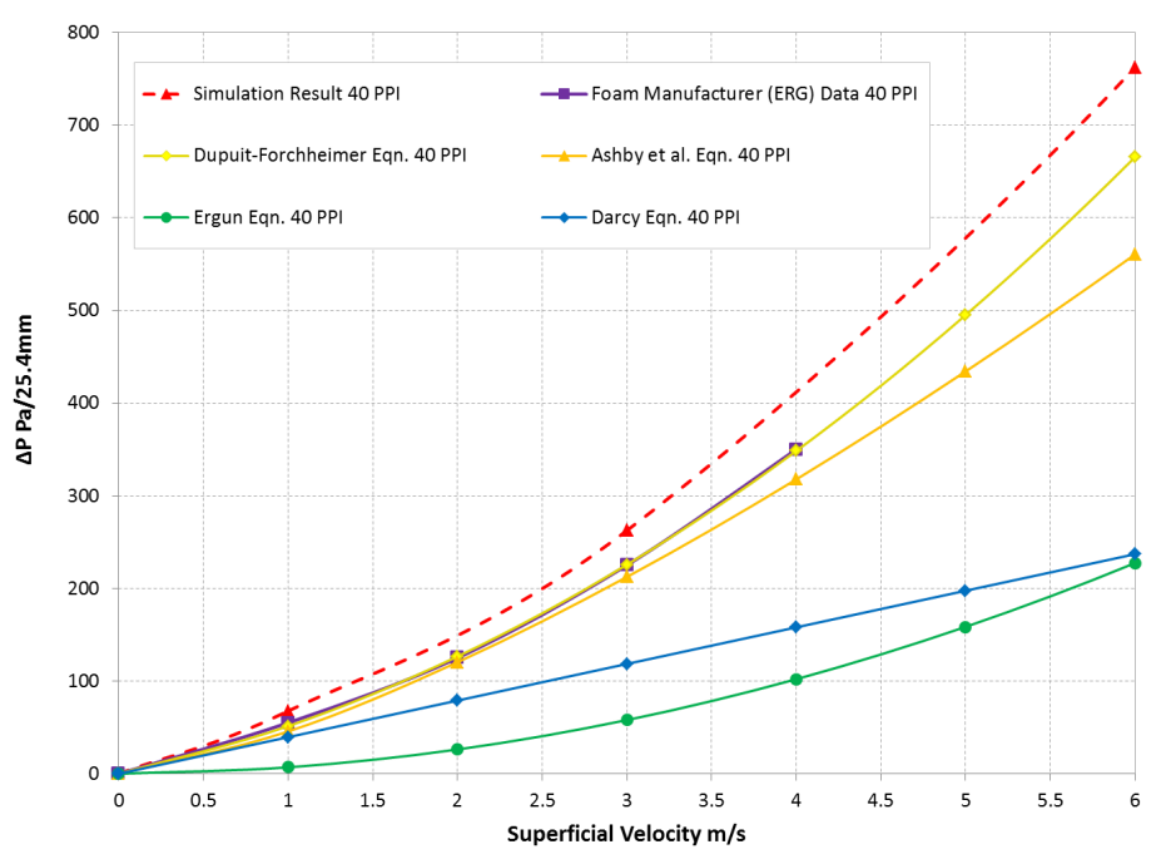

Figure 11 40ppi pressure drop comparison. 
The developed Representative Unit Cell Structure (RUCS) model for Open Pore Cellular Foam (OPCF) material, based on a dodecahedron cell is new to literature and proved more straightforward to implement compared to previous models, such as the tetrakaidecahedron cell, and more accurate than earlier spherical or rod models.

Analysis was completed for six different OPCFs, (10, 20, 30, 40, 45, 80 and 100ppi), at five different inlet velocities $(1 \mathrm{~m} / \mathrm{s}, 3 \mathrm{~m} / \mathrm{s}, 6 \mathrm{~m} / \mathrm{s}, 9 \mathrm{~m} / \mathrm{s} \& 12 \mathrm{~m} / \mathrm{s})$. A key parameter measured in this study was pressure drop through the model of each OPCF ppi type. A graphical summary of the models, not presented in the results section, are shown in Figure 12.

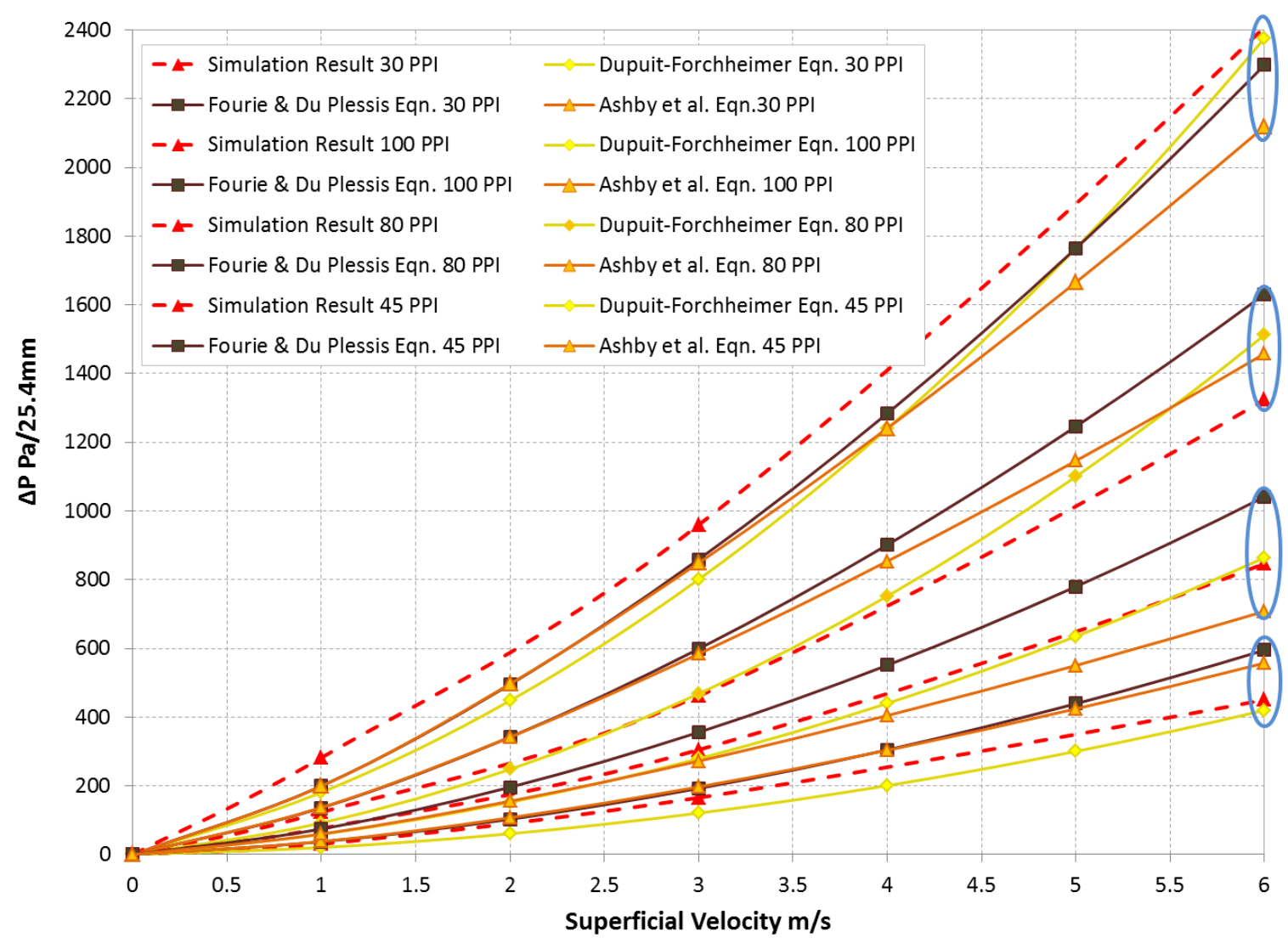

Figure 12 30, 45, $80 \&$ 100ppi pressure drop comparison.

Values of permeability (K) \& form coefficient (C) are important parameters when describing porous media. These values depend on the porous media type, thickness, fluid type and fluid velocity. Table 5 summarises the calculated values, from the manufacturer of the OPCF(for flow rates of $1 \mathrm{~m} / \mathrm{s}$ to $4 \mathrm{~m} / \mathrm{s}$ ), and the calculated values derived from the OPCF simulation results (for flow rates of $1 \mathrm{~m} / \mathrm{s}$ to $12 \mathrm{~m} / \mathrm{s}$ ). It is clear that both values do not correspond accurately, however this has also been noted in literature, as shown in Table 1. One explanation for this discrepancy is the different range of flow rates for both data sets, which can have an influence on the values as previously described by Dukhan and Minjeur [27]. Also the developed OPCF RUCS model, based on a dodecahedron cell, has simplified the foam composition into regular pores. Invariably all pores and ligaments may not be fully formed within a real sample and therefore results will differ slightly from a RUCS model. 
Table 5 OPCF calculated permeability (K) \& form coefficient (C) values.

\begin{tabular}{|c|c|c|c|c|}
\hline \multirow{2}{*}{ OPCF (ppi) } & \multicolumn{2}{|c|}{ Simulation result } & \multicolumn{2}{c|}{$\begin{array}{c}\text { Calculated values from } \\
\text { manufacturer data [38] }\end{array}$} \\
\cline { 2 - 5 } & $\mathrm{K}\left(\mathbf{m}^{2} \mathrm{E}-09\right)$ & $\mathrm{C}\left(\mathbf{m}^{-1}\right)$ & $\mathrm{K}\left(\mathrm{m}^{2} \mathrm{E}-09\right)$ & $\mathrm{C}\left(\mathrm{m}^{-1}\right)$ \\
\hline 10 & 704 & 95 & 181 & 154 \\
\hline 20 & 256 & 194 & 346 & 263 \\
\hline 30 & 161 & 229 & 38 & 307 \\
\hline 40 & 73 & 342 & 11 & 384 \\
\hline 45 & 64 & 368 & 11 & 557 \\
\hline 80 & 34 & 448 & 7 & 1039 \\
\hline 100 & 17 & 651 & 3 & 1384 \\
\hline
\end{tabular}

For all the models, the Dupuit-Forchheimer values matched exactly with the ERG data, since the K and $C$ values used to calculate it were obtained from the ERG experimental data as shown in Equation 4 and 12 in section 4. In general pressure drop results from the simulations are similar to, and matched very well with, available ERG experimental results, Dupuit-Forchheimer, Fourie \& Du Plessis, and Ashby mathematical models. Overall the developed model was most accurate at flow rates less than three meters per second across all the ppi types studied.

The Darcy and Ergun mathematical models do not align with the simulation results or the other models employed. The Darcy model is very useful when dealing with low Reynolds numbers and hence the form coefficient, $C$, is not accounted for in this model. Reynolds numbers calculated for the OPCF at the specified flow rates are detailed in Table 4 and therefore are larger than those normally used in the Darcy model. The Ergun model describes flow of a fluid past a collection of uniform spherical particles of specific diameter; however the OPCF is composed of triangular ligaments and not regular spherical particles.

The flow regime through the model can indicate potential benefits of the OPCF. For clarity Figures 5, 7 \& 9 show pressure and velocity results along the central plane of the model. A boundary layer was formed against the wall along the full domain of each model, however it is thinner in the foam region when compared to the inlet region. The pressure and velocity fields are symmetric at the input region but, depending on the pore size and position, the velocity field changes as it passes through the OPCF. Interestingly, the flow regime showed more mixing where ligament joints are slightly closer to the wall as shown in Figure 7 (b), (the left side ligament joints are closer to the wall than the right side joints).

The GDL and flow plate interface is very important in conventional flow fields such as serpentine; the flow is in the direction parallel to the electrode surface where the reactant flow to the catalyst layer is predominantly by molecular diffusion through the GDL [39]. This can lead to large concentration gradients across the GDL and mass transfer limitations because of the small channel dimensions, laminar gas flow and the inherent slow molecular diffusion process. It is also noted that permeability reduction with the conventional machined channel design is not possible beyond a particular value (around $10^{-8} \mathrm{~m}^{2}$ ), due to difficulty in machining thin cross-section channels [5] and increased velocity and pressure drop issues [40].

From this study, it is shown that the permeability of a fuel cell flow plate can be reduced by using OPCF material in place of conventional flow plates, producing a reduced pressure drop through such a flow plate, as shown by the low pressure drop results obtained for all OPCF models.

The ligaments, as shown in Figures 10, ensure a more tortuous path parallel to the plates thereby making the flow of reactant gases towards the wall (or reaction interface in a PEM fuel cell) from only diffusion to diffusion plus convection based, unlike conventional flow plates. For a tailored design a pressure drop allowance could be indicated and a specific ppi OPCF could be specified. 
The application of OPCF in PEM fuel cells, operating below $100^{\circ} \mathrm{C}$, will have liquid water present; hence it is necessary that if foams are to be used in PEM fuel cell applications water management would have to be examined. Foam materials may clog with water if not designed correctly. However many factors affect the ability of a material to operate in the PEM fuel cell environment, including its cost, weight, manufacturability, electrical and corrosion resistance, heat and water management as mentioned.

OPCF materials are extremely light, with a void fraction for most samples greater than $80 \%$, with potential benefits to future automotive fuel cell applications. OPCFs have been constructed from a variety of metals, including aluminium, stainless steel and nickel, which have good electrical and heat conductivity and if protected, with a coating, may have high corrosion resistance as well as enhanced hydrophobic properties. Without further research, understanding the potential performance of OPCF material for PEM fuel cell flow plate applications is difficult.

If an OPCF material is constructed from the correct material and designed effectively for a flow plate application, representative models will be required to understand fluid behaviour. This study has focused on the fluid behaviour through OPCF, in a PEM fuel cell application. The key issues when designing a flow plate are: the even distribution of pressure on the GDL and membrane, low pressure drop in and through the flow plate, distribution of temperature on the GDL and membrane, maintained reactant concentration over the entire active area of the GDL and membrane, membrane hydration and the mitigation of flooding.

Applying OPCF materials to PEM fuel cells could help to reduce mass transport losses, increasing the PEM fuel cell performance and better power density on both volume and weight basis (due to reduced mass using foams). The need for expensive machining process to manufacture flow plates could be eliminated using OPCF, once formed, they need only be cut to size for a fuel cell application.

The ultimate goal of this body of work is to improve the performance of PEM fuel cells and in the process try to simplify their design to reduce material, manufacturing and assembly costs focusing on flow plate development.

\section{CONCLUSION}

The conclusions resulting from the investigation are summarised as follows:

- A Representative Unit Cell Structure (RUCS) model for Open Pore Cellular Foam (OPCF) material was proposed and developed.

- Pressure drop calculations from the simulations are similar to, and matched very well with, available ERG experimental results, Dupuit-Forchheimer, Fourie \& Du Plessis, and Ashby mathematical models. The Darcy (due to high Reynolds number) and the Ergun mathematical models (due to lack of spherical particles) do not align as well.

- OPCF can ensure a tortuous gas flow through the structure and provide a low pressure drop from inlet to outlet.

- Applying these materials to fuel cells could help to reduce mass transport losses, increasing the PEM fuel cell performance.

- This work sets down a model that future designers and modellers can use for many applications including PEM fuel cells. 


\section{References}

[1]Carton JG, Olabi AG. Wind/hydrogen hybrid systems: Opportunity for Ireland's wind resource to provide consistent sustainable energy supply. Energy 2010;35(12):4536-4544.

[2]Achour H, Carton JG, Olabi AG. Estimating vehicle emissions from road transport, case study: Dublin City. Applied Energy 2011;88(5):1957-1964.

[3]Lawlor V, Zauner G, Hochenauer C, Mariani A, Griesser S, Carton JG, et al. The Use of a High Temperature Wind Tunnel for MT-SOFC Testing-Part I: Detailed Experimental Temperature Measurement of an MT-SOFC Using an Avant-Garde High Temperature Wind Tunnel and Various Measurement Techniques. Journal of Fuel Cell Science and Technology 2010 12;7(6):061016 (7 pp.).

[4]O'Hayre R, Cha S, Colella W, Prinz FB. Fuel Cell Fundamentals. USA: John Wiley and Sons; 2006.

[5]Kumar A, Reddy RG. Materials and design development for bipolar/end plates in fuel cells. Journal of Power Sources 2004;129(1):62-67.

[6]Carton JG, Lawlor V, Olabi AG, Hochenauer C, Zauner G. Water droplet accumulation and motion in PEM (Proton Exchange Membrane) fuel cell mini-channels. Energy 2012;39(1):63-73.

[7]Steele BCH, Heinzel A. Materials for fuel-cell technologies. Nature 2001;414(6861):345-352.

[8]Carton JG, Olabi AG. Design of experiment study of the parameters that affect performance of three flow plate configurations of a proton exchange membrane fuel cell. Energy 2010;35(7):27962806.

[9]Ashby MF, Evans AG, Fleck NA, Gibson LJ, Hutchinson JW, Wadley HNG. Metal Foams: A design Guide. 1st ed. Massachusetts: Butterworth-Heinemann; 2000.

[10]Friedrich JM, Ponce-de-Leon C, Reade GW, Walsh FC. Reticulated vitreous carbon as an electrode material. J Electroanal Chem 2004;561(1-2):203-217.

[11]Du Plessis P, Montillet A, Comiti J, Legrand J. Pressure drop prediction for flow through high porosity metallic foams. Chemical Engineering Science 1994;49(21):3545-3553.

[12]Watkins D, Dircks K, Epp D, inventors. Watkins D, Dircks K and Epp D, assignees. Fuel cell with a fluid flow field plate. EU patent 04157331991.

[13]Tang Y, Yuan W, Pan M, Wan Z. Feasibility study of porous copper fiber sintered felt: A novel porous flow field in proton exchange membrane fuel cells. Int J Hydrogen Energy 2010 9;35(18):9661-9677.

[14]Tsai B, Tseng C, Liu Z, Wang C, Lee C, Yang C, et al. Effects of flow field design on the performance of a PEM fuel cell with metal foam as the flow distributor. Int J Hydrogen Energy 2012 9;37(17):13060-13066.

[15]Bidault F, Brett DJL, Middleton PH, Abson N, Brandon NP. A new application for nickel foam in alkaline fuel cells. Int J Hydrogen Energy 2009 8;34(16):6799-6808. 
[16]Stone HA, Evans AG, Bastawros AF. Evaluation of cellular metal heat transfer media. 1998; , MECH 325.

[17]Lu TJ, Stone HA, Ashby MF. Heat transfer in open-cell metal foams. Acta Materialia 1998 06/12;46(10):3619-35.

[18]Shankar Krishnan, Suresh V. Garimella and Jayathi Y. Murthy. Simulation of thermal transport in open-cell metal foams: Effect of periodic unit cell structure. Anonymous International Mechanical Engineering Congress and Exposition, IMECE2006, November 5 -November 10 Chicago, IL, United states: American Society of Mechanical Engineers; 2006; .

[19]Krishnan S, Murthy JY, Garimella SV. A two-temperature model for solid-liquid phase change in metal foams. Journal of Heat Transfer 2005;127(9):995-1004.

[20]Fourie JG, Du Plessis JP. Pressure drop modelling in cellular metallic foams. Chemical Engineering Science 2002;57(14):2781-2789.

[21]Boomsma K, Poulikakos D, Ventikos Y. Simulations of flow through open cell metal foams using an idealized periodic cell structure. Int J Heat Fluid Flow 2003;24(6):825-834.

[22] Xu W, Zhang H, Yang Z, Zhang J. Numerical investigation on the flow characteristics and permeability of three-dimensional reticulated foam materials. Chem.Eng.J. 2008 7/1;140(1-3):562569.

[23]Ozmat B, Leyda B, Benson B. Thermal applications of open-cell metal foams. Mater.Manuf.Process. 2004;19(5):839-62.

[24]Medraj M, Baril E, Loya V, Lefebvre L-. The effect of microstructure on the permeability of metallic foams. J.Mater.Sci. 2007 06;42(12):4372-83.

[25]Dukhan N. Correlations for the pressure drop for flow through metal foam. Exp.Fluids 2006 10;41(4):665-72.

[26]David P. Haack, Kenneth R. Butcher, T. Kim and T. J. Lu. Novel Lightweight Metal Foam Heat Exchangers. Anonymous International Mechanical Engineering Congress and Exposition, November 11 - November 16 New York, NY, United states: American Society of Mechanical Engineers; 2001; 141-147.

[27]Dukhan N, Minjeur II CA. A two-permeability approach for assessing flow properties in metal foam. Porous material 2011;18:417-424.

[28]Cavallini A, Mancin S, Rossetto L, Zilio C. AIR flow in aluminum foam: Heat transfer and pressure drops measurements. Exp.Heat Transfer 2010;23(1):94-105.

[29]Wilson L, Narasimhan A, Venkateshan SP. Permeability and form coefficient measurement of porous inserts with non-darcy model using non-plug flow experiments. J Fluids Eng Trans ASME 2006;128(3):638-642.

[30]Krishnan S, Murthy JY, Garimella SV. Direct simulation of transport in open-cell metal foam. Journal of Heat Transfer 2006;128(8):793-799. 
[31] Kopanidis A, Theodorakakos A, Gavaises E, Bouris D. 3D numerical simulation of flow and conjugate heat transfer through a pore scale model of high porosity open cell metal foam. Int.J.Heat Mass Transfer 2010 5;53(11-12):2539-2550.

[32] Gerbaux O, Buyens F, Mourzenko VV, Memponteil A, Vabre A, Thovert J-, et al. Transport properties of real metallic foams. J.Colloid Interface Sci. 2010 2/1;342(1):155-165.

[33]Zahi I, Rossi C, Faucheux V. Micro PEM fuel cell current collector design and optimization with CFD 3D modeling. Int J Hydrogen Energy 2011 11;36(22):14562-14572.

[34] Liu H, Li P, Lew JV. CFD study on flow distribution uniformity in fuel distributors having multiple structural bifurcations of flow channels. Int J Hydrogen Energy 2010 9;35(17):9186-9198.

[35]Barreras F, Lozano A, Valiño L, Marín C, Pascau A. Flow distribution in a bipolar plate of a proton exchange membrane fuel cell: experiments and numerical simulation studies. J.Power Sources 2005 6/1;144(1):54-66.

[36] Kim TH, Lee $\mathrm{W}$, Jeong JH. Thermo-fluidic characteristics of open cell metal foam as an anodes for DCFC, part I: Head loss coefficient of metal foam. Int J Hydrogen Energy 2014;39(23):12369-12376.

[37]Fluent Inc. Fluent Manual \& Theory Guide. U.S.,2010. See Also: Accessed through www.ansys.com.

[38]ERG Materials and Aerospace Corp. Material Specific Properties of Metal Foam. US,2009. See Also: http://www.ergaerospace.com/.

[39]Kazim A, Liu HT, Forges P. Modelling of performance of PEM fuel cells with conventional and interdigitated flow fields. J.Appl.Electrochem. 1999 12;29(12):1409-16.

[40]Spiegel CS, Agarwal R, Bhansali S. Comparison of microchannel dimensions for air-breathing polymer exchange membrane microfuel cells. J.Power Sources 2008 08/01;182(2):603-8. 